\title{
PAR INDEX IN THE EVALUATION OF THE STABILITY OF THE ORTHODONTIC TREATMENT RESULTS. A REVIEW
}

\begin{abstract}
Chaitra Ramanathan
Charles University in Prague, Faculty of Medicine in Hradec Králové and University Hospital Hradec Králové, Czech Republic: Department of Dentistry

Summary: The evaluation of the treatment results is normally done to estimate the nature and quality of work, so that justice can be done to the work that we do and also that the patients will be satisfied. The primary motive of every orthodontist should be to treat the patient effectively and successfully with long lasting results. Thus the patients are to be assessed, using an appropriate method. PAR index was developed in the recent years to evaluate the treatment results and it is considered as a simple, objective and a reliable manner for evaluating the stability after orthodontic treatment. The index can be applied to different components of the dentition and scores are applied to each component after which the individual scores are multiplied with their respective weightings to balance the impact of the individual components of the overall result. They are then summed up to establish an overall total. In this manner, the method was carried out for the study casts of the three different phases of the treatment i.e. before the onset of the treatment, immediately after treatment and 2 years after treatment for assessing the stability after orthodontic treatment.
\end{abstract}

Key words: Orthodontic treatment; Stability; Index

\section{Introduction}

Assessing the stability after orthodontic treatment is a subject of interest as it helps to evaluate the post treatment results and thereby the quality of the work. Evaluating these post treatment results and assessing the orthodontically treated long-term post treatment results has been a topic of interest from several decades (13). Stability refers to a state, which does not change but instead remains constant in nature. Long- term post treatment stability is an issue of great concern to all orthodontists, as stability at the end of the result is one of prime objectives of orthodontic treatment, for without stability neither proper function nor esthetics can be maintained.

\section{Stability of the orthodontic treatment results}

Although we know that the stability after orthodontic treatment is essential for maintaining function and esthetics of an individual, it seems that a large variability in orthodontic treatment outcome exists for different individuals. The variabilities could be a result of various factors like treatment approach, co-operation of patient, growth and adaptability of the hard and soft tissues. Also, many additional factors are known to influence stability after orthodontic treatment. These additional factors include the type, duration and the timing of the retention appliance $(11,15)$. Also, many studies have been found that have described the long-term stability of specific type of malocclusions $(7,13$, 14, 16). Few other studies showed the stability of orthodontic treatment outcome longitudinally for specific occlusal traits such as open bite, overjet, overbite, cross bite, intercanine and intermolar distance and lower anterior crowding (5). Thus a lot of factors are to be taken into account to establish stability after orthodontic treatment and in order to maintain and improve the stability after establishing the results, it is advisable to assess the stability after treatment.

Further studies have shown that the comparison of pretreatment, immediate post treatment and post treatment after few years can be done to assess the stability $(19,20)$. The study casts of pre treatment, immediate post treatment and post treatment after few years can be used for this purpose and it can be assessed to improve the quality of future treatments $(10,11)$ and occlusal indices have been developed to assess treatment standards and to determine the success of the treatment $(4,8,10)$. While using an index, usually the scores are applied to the dental features of a certain malocclusion and the sum of these scores ranks the malocclusion, to which a weighting is then added (6). Many indices were developed over the years and each of it has its own advantages and disadvantages. 


\section{PAR index and its use}

In order to overcome the difficulties created by using indices inappropriately, two indices were developed. One to measure the orthodontic treatment need called the Index of treatment need (IOTN) and the other to assess the standard of treatment called the Peer Assessment Rating index (PAR index).

PAR index was introduced by S. Richmond and it was mainly developed to record the malocclusion in the mixed and permanent dentition. The index was formulated over a series of six meetings in 1987 with a group of 10 expe-

Tab. 1: Contact point displacements. Scores and their respective displacements to be used while assessing the alignment of anterior segment of the dentition.

\begin{tabular}{|c|l|}
\hline Score & Displacements \\
\hline 0 & 0 to $1 \mathrm{~mm}$ \\
\hline 1 & 1.1 to $2 \mathrm{~mm}$ \\
\hline 2 & 2.1 to $4 \mathrm{~mm}$ \\
\hline 3 & 4.1 to $8 \mathrm{~mm}$ \\
\hline 4 & Greater than $8 \mathrm{~mm}$ \\
\hline 5 & Impacted teeth \\
\hline
\end{tabular}

rienced orthodontists (18). The index is considered as a simple, objective and a reliable manner (19) for evaluating the stability after orthodontic treatment. Several studies have been conducted which demonstrate the method for assessing the stability after orthodontic treatment using the PAR index $(1,2,9,12,17,21,22)$. According to the rules of the PAR index, each of the components of the dentition i.e. anterior segment (upper and lower), buccal segment relationships on both sides, overjet, overbite and midline discrepancies can be scored, which is then multiplied with their respective weightings after which the overall score is established. In this way each components are to be assessed for the three different phases of treatment i.e. the pre treatment, post treatment and 2 years post treatment study casts for assessing the stability.

Tables 1-5 show scoring system for each component of the dentition by PAR index. According to the PAR system, there exists a PAR index ruler, which is designed to facilitate an easy measurement for recording the malocclusion of the dentition. The ruler has certain information's in it that it is capable of summarizing the complete details and thereby is known to facilitate a quick assessment of the study.

There are basically three methods of assessing improvement using the PAR index $(9,20)$.

Tab. 2: Scores in all three planes of space to be used while assessing the buccal segment relationship.

\begin{tabular}{|c|c|c|}
\hline Antero posterior relation & Vertical relation & Transverse relation \\
\hline Score & Score & Score \\
\hline \multirow{2}{*}{$\begin{array}{c}0 \text { - Good interdigitation } \\
\text { (Class I, II, III) }\end{array}$} & 0 - No open bite & 0 - No cross bite \\
\hline & \multirow{2}{*}{\begin{tabular}{|l|}
1 - Lateral open bite on at least \\
two teeth greater than $2 \mathrm{~mm}$
\end{tabular}} & $1-$ Cross bite tendency \\
\hline \multirow{2}{*}{$\begin{array}{l}1 \text { - Less than half from full } \\
\text { interdigitation }\end{array}$} & & 2 - Single tooth in cross bite \\
\hline & & 3 - More than one tooth in cross bite \\
\hline 2 - Half a unit (cusp to cusp) & & 4 - More than one tooth in scissor bite \\
\hline
\end{tabular}

Tab. 3: Scores to be used while assessing the overjet.

\begin{tabular}{|l|l|}
\hline Overjet & Anterior cross bites \\
\hline Score & Score \\
\hline $0-0$ to $3 \mathrm{~mm}$ & 0 - No cross bite \\
\hline $1-3.1$ to $5 \mathrm{~mm}$ & 1 - One or more teeth edge to edge \\
\hline $2-5.1$ to $7 \mathrm{~mm}$ & 2 - One single tooth in cross bite \\
\hline $3-7.1$ to $9 \mathrm{~mm}$ & 3 - Two teeth in cross bite \\
\hline $4-$ Greater than & $\begin{array}{c}4-\text { More than two teeth in cross } \\
\text { bite }\end{array}$ \\
\hline
\end{tabular}

Tab. 5: Scores for recording the midline that are needed to assess the midline discrepancies.

\begin{tabular}{|c|}
\hline Centerline \\
\hline Score \\
\hline 0 - Coincident and upto one quarter lower incisor width \\
\hline 1 - One quarter to one half lower incisor width \\
\hline 2 - Greater than one half lower incisor width \\
\hline
\end{tabular}

Tab. 4: Scores to be used while assessing the overbite.

\begin{tabular}{|l|l|}
\hline Open bite & Overbite \\
\hline Score & Score \\
\hline 0 - No open bite & $\begin{array}{c}0 \text { - Less than or equal to one third } \\
\text { coverage of the lower incisor }\end{array}$ \\
\hline $\begin{array}{c}1 \text { - Open bite less } \\
\text { than or equal } \\
\text { to } 1 \mathrm{~mm}\end{array}$ & $\begin{array}{c}1 \text { - Greater than one third but less } \\
\text { than two thirds coverage of the } \\
\text { lower Incisor }\end{array}$ \\
\hline $\begin{array}{c}2 \text { - Open bite } \\
1.1 \text { to } 2 \mathrm{~mm}\end{array}$ & $\begin{array}{c}\text { - Greater than two thirds } \\
\text { coverage of the lower incisor }\end{array}$ \\
\hline $\begin{array}{c}3 \text { - Open bite } \\
2.1 \text { to } 4 \mathrm{~mm}\end{array}$ & $\begin{array}{c}3 \text { - Greater than or equal to full } \\
\text { tooth coverage }\end{array}$ \\
\hline $\begin{array}{c}4-\text { Open bite } \\
\text { greater than } \\
4 \mathrm{~mm}\end{array}$ & \\
\hline
\end{tabular}




\section{a) Absolute reduction in the weighted PAR score}

The absolute or the exact reduction in the weighted PAR score reading means the PAR score that can be obtained by deducting of the weightings of pre treatment scores with the weightings of the immediate post treatment scores. This helps in assessing the improvement or deterioration of the results. Also on deducting the weightings of the immediate post treatment score with the weightings of the post treatment scores after few years. It is possible to determine the persistence or deterioration of stability after treatment.

\section{b) Assessing using the nomogram}

During the study, if the nomogram is used to assess the improvement of the PAR index, then a nomogram is plotted using the pre treatment weighted PAR score on the horizontal ' $x$ ' axis and the post treatment weighted PAR score on the vertical ' $y$ ' axis, i.e. the pre and the post treatment scores are read on their respective axis. Where the intercept falls, it indicates the degree of improvement that only provides three broad bands of treatment change $(9,10,11,12,13)$ :

- worse - no different,

- improved,

- greatly improved.

Similarly the immediate post treatment scores are plotted on the horizontal ' $x$ ' axis and post treatment scores after few years on the vertical ' $y$ ' axis to assess the stability. After knowing the result it is possible to categorize the results obtained. For example, a high standard of treatment is achieved when the proportion of cases falling into "worse or no different" category of an individuals case is negligible and the mean percentage reduction in weighted PAR score is high, e.g. greater than 70 percent $(7,12)$.

It is possible to understand from the above nomogam (Fig. 1) that the ' $x$ ' axis is a presentation of scores before treatment with the scores starting from 0 to 60 with a difference of 5 points between the scores. The ' $y$ ' axis is a presentation of scores after treatment with the scores starting from 0 to 45 , also with a difference of 5 points between the points. The lines in the nomogram represents the demarcation between the worse or no different cases, improved and the greatly improved bands of treatment change. For example: The point in the no different band of treatment change indicates that the treatment was without improvement.

Similarly, the point in the second category of treatment change shows that the treatment was with good improvement. The second category of treatment change represents PAR points of less than 22. This category shows the significant difference after treatment. It helps a clinician to evaluate the quality of work, by helping to estimate whether there was really some significant improvement or not after treatment. For example, the point in the improved category indicating that the treatment results were with significant improvement (Fig. 2).

On the other hand the point in the third category of treatment change shows that the treatment was with improve-

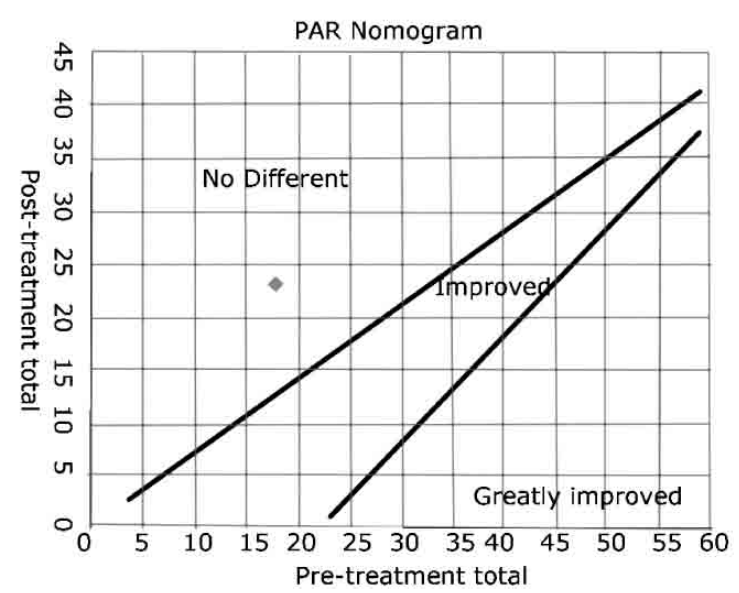

Fig. 1: The presence of the point in the No different catego$r y$ of the nomogram indicates that the treatment was without improvement.

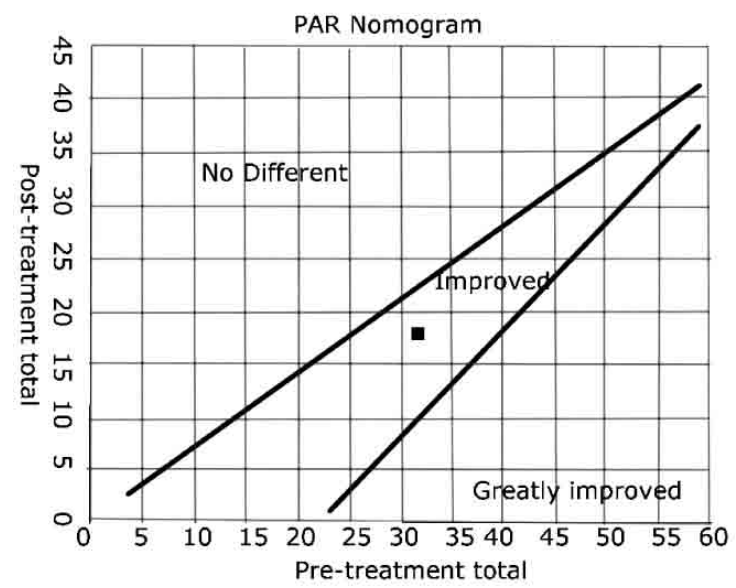

Fig. 2: The presence of the point in the Improved category of the nomogram indicates that the treatment was with good improvement.

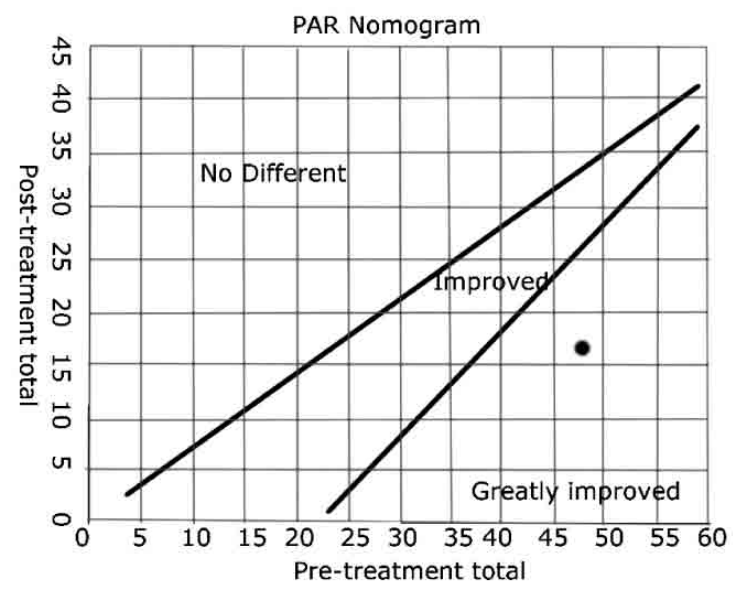

Fig. 3: The presence of the point in the Greatly improved category of the nomogram indicates that the treatment was with excellent improvement. 
ment to a larger extent. The third category of treatment change represents PAR points of greater than 22. This category also shows the significant difference after treatment. It helps a clinician to evaluate the quality of work, by helping to estimate whether there was really greater improvement or not after treatment. For example, the point in the greatly improved category indicating that the treatment results were with greater improvement (Fig. 3).

\section{c) Percentage reduction in the weighted PAR score}

The percentage reduction method of detecting the improvement of orthodontic treatment is known to reflect the change relative to the pre treatment score. For example, a case in which the score is from 4 to 10 would represent $76.9 \%$ improvement. Accordingly a high standard of treatment was considered as being achieved when the percentage reduction in weighted PAR score was high.

After assessing the scores obtained by any of the three methods of assessment, the result obtained can be further evaluated. A high standard of treatment is known to be achieved:

- when the proportion of cases falling into "Worse or no different" category is negligible,

- when the mean percentage reduction in weighted PAR score is high.

Also, when a percent of greater than $30 \%$ suggests that the practitioner is treating a large number of cases to a comparatively good standard. Thus in this way, the quality of work of an orthodontist can be obtained. The stages of improvement can be classified as represented by Tab. 6 .

Tab. 6: The values for each stages of improvement (taken from Spidlen, M. et al.: Efektivita ortodontické léčby, 2003).

\begin{tabular}{|l|c|c|}
\hline Improvement & $\begin{array}{c}\text { Nomogram } \\
\text { classification }\end{array}$ & $\begin{array}{c}\text { PAR score } \\
\text { change } \\
\text { (Percentual } \\
\text { reduction) }\end{array}$ \\
\hline Worse or no different & $<30 \%$ & $<30 \%$ \\
\hline Improved & $>=30 \%,<22$ PAR & $30-70 \%$ \\
\hline Greatly improved & $>=22$ PAR & $>70 \%$ \\
\hline
\end{tabular}

\section{Discussion}

The availability of a definition for normal occlusion (3) set a standard for comparison of treatment outcomes. The six keys of occlusion that contribute to normal occlusion were introduced by Andrews during the 1970's. According to Andrews the presence of these features were essential to achieve an optimal oclusion. The six keys to normal occlusion are molar inter-arch relationship, mesio-distal crown angulation, labio-lingual crown inclination, absence of rotation, tight contacts and curve of Spee. Thus in order to detect the clear definition of what constitutes a deviation from normal occlusion, it became neccessary to increase the subjectivity of asessing results.
Besides this the grading of orthodontic treatment results at study group meetings has been practised for many years. The concept of individuals grading their own treatment results can be a self-teaching device and may improve the quality of future treatment. In the field of research the need for accurate measure is even more critical.

One of the possible ways to assess the treatment results and to compare it with the normal occlusion is by the way of assesing it with the indices. Several orthodontic indices have been developed to assess the treatment need and outcome.

But many of the indices have their own limitations. Basic requirement for use of an index is to be valid, reliable easy to use and to amend for modification. PAR index is one of them and is known to satisfy all the required objectives. It measures occlusal characteristics and has been used for assessment over the years after its introduction into the field of orthodontics. The PAR index is a weighted combination of seven occlusal triats, upper and lower anterior alignment, right and left buccal occlusion, overjet, overbite and centreline. Later the weightings for the separate components were derived from the validation studies that were done due to the panel assessment study.

\section{Conclusions}

The experience of the PAR index is still at an early stage, although several practical uses are described that the PAR index has an excellent validity that has been demonstrated and has also been tested in a series of investigations. Intra examiner reliability was also excellent $(6,16,18,21)$. Thus finally according to the study of Dr. Richmond, it was said that it was possible to teach staff without dental qualification or training to use the weighted PAR index to a high level of reliability. Thus in this way, the PAR index can be used for assessing the stability after orthodontic treatment.

\section{References}

1. Afsharpanah A, Feghali R, Hans MG, Nelson S. Assessment of orthodontically untreated adolescents using the PAR index. J Dent Res 1996; 75 (AADR Abstract): 363 .

2. Afsharpanah A, Nelson S, Feghali R, Hans MG. Assessment of orthodontically untreated sample using the PAR index. J Dent. Res 1995; 74 (AADR Abstracts): 139.

3. Andrews L F. The six keys to normal occlusion. Amer J Orthodont dentofacial Orthop 1972; 62: 296-309.

4. Berg R, Fredlund A. Evaluation of orthodontic treatment results. Eur J Orthodont 1981; 3: 181-5.

5. Brook P, Shaw W. The development of an index of orthodontic treatment priority. Eur J Orthodont 1989; 11: 309-20.

6. Buchanan I B, Shaw WC, Richmond S, O'Brien KD, Andrews M. A comparison of the reliability and validity of the PAR index and Summers' occlusal index. Eur J Orthodont 1993; 18: 27-31.

7. Elms TN, Buschang MA, Alexander RG. Long term stability of class II div I non -extraction cervical face bow therapy: I model analysis. Amer J Orthod dentofac Orthop 1996; 109: 271-6.

8. Eismann D. A method of evaluating the efficiency of orthodontic treatment Transactions of the European Orthodontic Society 1974; 223-32.

9. Fox NA. The first 100 cases: a personal audit of orthodontic treatment assessed by the PAR (Peer Assessment Rating) Index. Brit Dent J 1993; 174: 290-7.

10. Hamdan AM, Rock WP. An appraisal of the Peer Assessment Rating (PAR) Index and a suggested new weighting system. Eur J Orthodont 1999; 21: 181-92. 
11. Hickham JH. Directional edgewise orthodontic approach. Journal of Clinical Orthodont 1975; 9: 143-54

12. Kerr WJS, Buchanan IB. Use of the PAR Index in Assessing the Effectiveness of Removable Orthodontic Appliances. Brit J Orthodont 1993; 20: 351-7.

13. Little RM. Stability and relapse of dental arch alignment: review article. Brit J Orthodont 1990; 17: 235-41.

14. Little RM, Riedal RA, Stein A. Mandibular arch length increase during the mixed dentition, post retention evaluation of stability and relapse. Amer J Orthod dentofac Orthop 1990; 97: 393- 404.

15. Nanda RS, Nanda SK. Considerations of dentofacial growth in long -term retention and stability, an active retention needed. Amer J Orthodont dentofac Orthop 1992; 101: 297-302.

16. O'Brien K, Robbins R, Vig KWL, Shnorhokian H, Weyant RJ. The effectiveness of Class II, Division 1 treatment. Amer J Orthodont. Dentofacial Orthop 1995; 107: $329-34$.
17. Otuyemi OD, Jones SR. Long-term evaluation of treated Class II Division 1 malocclusion utilizing the PAR index. Brit J Orthodont 1995; 22: 171-8.

18. Richmond S, Shaw WC, Roberts CT, Andrews W. The PAR Index (Peer Assessment Rating): Methods to determine outcome of orthodontic treatment in terms of improvement and standards. Eur J Orthodont 1992; 14: 180-7.

19. Richmond S, Andrews M. Orthodontic Treatment Standards in Norway. Eur J Orthodont 1993; 15: 7-15.

20. Richmond S, O’Brien KD, Buchanan IB, Burden DJ. An introduction to Occlusal Indices, University of Manchester, Bradford, England, Ortho-Care (UK) Ltd. 1994

21. Shaw WC, Richmond S, O'Brien KD and Brook PH. Quality control in orthodontics: Indices of treatment need and treatment standards. Brit Dent J 1991; 170: $107-112$.

22. Spidlen M, Kotas M, Machytkova G, Gvuzdova K. Effectiveness of orthodontic treatment with removable and fixed appliances. Ortodoncie 2004; 4: 21-31.

Submitted October 2006. Accepted December 2006.

\section{Corresponding author:}

Chaitra Ramanathan, BDS, University Hospital Hradec Králové, Department of Dentistry, Sokolská 581, 50005 Hradec Králové, Czech Republic, e-mail: chaitra_ramanathan@yahoo.co.in 